\title{
Comparative Effectiveness of Value Clarification and Role Playing Value Development Models for Selected Values for Primary School Students
}

\author{
Dr. Roli Rai \\ Associate Professor, Department of Education, NIEC, BBDGEI, Lucknow, India
}

\begin{abstract}
Our society is currently at a crossroads and an urgent need to revamp our present education system so that it morphs into a pivotal tool in developing values. Is required Value Education a model of teaching - a way of thinking? With the need for value inculcation realized, we must address the vehicles for executing the same. In this regard, various value development models have been suggested. An education setting model of value education includes a theory about how people develop morally and myriad strategies for fostering moral development. Of these various Value Development Models two models that seem to be appropriate in inculcating desirable values in students and being feasible enough for widespread implementation are the Value Clarification and Role Playing Models. Since both the Value Development Models are supposed to be quite effective, a study was conducted to compare the effectiveness of both Value Clarification and Role Playing Models so that either one of them could be used as an effective tool in inculcating desirable values in classroom situations. It was found that both the Value Clarification Model and Role Playing Model proved to be nearly equally effective as far as the inculcation of the selected values on primary school children was concerned.
\end{abstract}

Keywords: Primary School Students, Value Clarification, Role Playing, Value Development Models

\section{Introduction}

With the social and national disintegration gradually eroding the fundamental set-ups of our society, we are now facing a dire need to overhaul the system. The new generation is drifting away from its history and culture. Crime, violence and sheer apathy to human suffering have spread to all spheres of life. Doubtless, the scientific discoveries have given rise to genuine optimism and materialistic accomplishments, but the problems of inequity, conflicts, poverty, apathy and anxiety are on the rise. This has proven that there is a great inadequacy in our system and the education given in science and technology to our youth has failed to inculcate human morals.

Our society is currently at a crossroads. The need of the hour is not to circumspect but to introspect. Values are determiners of choices in life and thus they decide the behavior and aid the masses in resolving the conflicts that come their way. There is an urgent need to revamp our present education system so that it morphs into a pivotal tool in developing values. In today's classrooms the emphasis is on increasing the academics of students rather than desirable values and bringing about changes in attitudes. Teachers hardly get time to teach in a way that help in solving day to day problems of the people - leave alone resolve conflicts by taking right decisions in life. Students too, do not get time to mould their behavior in this direction as they are over-loaded with the curriculum and many non-academic activities.

"Of twenty one notable civilizations, nineteen perished not from conquest from without but from decay from within." These words of the famous historian Arnold Toynbee sound a warning to every modern society that refuses to accept "values" that are no longer popular with the masses.

In Allport's words (1960): "A value is a belief upon which a man acts by giving preference".

"A value system is an enduring organization of beliefs concerning preferable modes of conduct or end states of existence along a continuum of relative importance." (Rokeach 1973)

In order to strike a compromise between increasing globalization and the need for preservation of national cultural Identity, Delors Commission (1996) has laid emphasis on the need to expand the canvas of universal values by incorporating awareness of human rights combined with a sense of social responsibility. Value Education is a model of teaching - a way of thinking and doing for the development of morals.

\section{Value Development Models}

With the need for value inculcation realized, we must address the vehicles for executing the same. In this regard, various value development models have been suggested. An education setting model of value education includes a theory about how people develop morally and myriad strategies for fostering moral development. The models of Value Education provide a broad based pedagogy to mobilize feeling, guide 
thinking and to sustain action. In order to develop human values various Value Development Models were developed, such as-

- Jurisprudential Inquiry Model

- Rationale Building Model

- Consideration Model

- Value Analysis Model

- Cognitive Moral Development Model

- Social Action Model

- Value Discussion Model

- Value Clarification Model

- Role Playing Model

Of these various Value Development Models two models that seem to be appropriate in inculcating desirable values in students and being feasible enough for widespread implementation are the Value Clarification and Role Playing Models. Since both the Value Development Models are supposed to be quite effective, a study was conducted by the investigator to compare the effectiveness of both Value Clarification and Role Playing Models so that either one of them could be used as an effective tool in inculcating desirable values in classroom situations.

\subsection{Value Clarification Model}

Value Education based on Value clarification approach originated in 1960's, ushered by Rath et al (1966) ,and Oliver and Shaver(1966) Here the role of an instructor is said basically to help the child to clarify his values; the main purpose being to help the students use rational thinking and develop awareness of not only their personals but also of social values. Contrary to first guesses, Value Clarification does not tell a person what his values should be, or what values he should live by; but it simply provides the means to discover what values to live by .This model analyses relationship between values and behaviour. Mostly, lack of values in pupils ends in their maladjustment and also the various problems are exhibited in school or home. This model points out how we see ourselves in relation to society. Supporters of the theory further state that those who are clear about their relation with society exhibit positivity, eagerness, and diligence, while those who are confused exhibit tendencies of negativity, inconsistency, drifting and over-dissenting Hersh (1982).

\subsection{Role Playing Model}

Role Playing Model is an often opted for alternative to the aforementioned Value Clarification Model. This model demands much more active participation from students but, as we will see later in this paper, is considered to be more effective as well. Role Playing was formulated by Fannie and George Shaftel (1967). Some ideas have also been incorporated from the works of Mark Chesler and Robert Fox (1966). As given by Bruce Joyce, Role Playing helps students explore human relations- by enacting problems and then discussing the enactment, students together can explore feelings, values and problem-solving strategies. Role Playing as a model of teaching has roots in both personal and social dimensions of education. This helps individuals resolve personal dilemmas with the assistance of social groups. Regarding the social dimensions individuals work together and analyze social situations, with special reference to interpersonal problems.

Herein, some students are given the part of role-players, while the rest are observers. Each person puts himself in the position of another person and then tries to interact with others who are playing roles. Doing so generates not just sympathy, but empathy. We learn to put ourselves in others' shoes and consider problems with different perspectives. As empathy, sympathy, love, and friendship are generated during the interaction, role playing will be effectively carried out. Thus in order to have a clear understanding of oneself, understanding of others too, is essential. As Bruce Joyce puts it, "The essence of role playing is the involvement of participants and observers in a real problem situation and the desire for resolution and understanding that this involvement engenders."

\subsection{Objectives of the study}

1. To identify values relevant for primary school students in today's context.

2. To develop lesson plans for Value Clarification \& Role playing models upon identified values.

3. To execute the transactional plan on primary school students.

4. To compare the effectiveness of Value Clarification and role playing Value Plan Models with respect to development of identified values in primary school students. 


\subsection{Hypothesis (For Objective 4)}

Since this is an experimental study the following hypothesis has been made, i.e. there is no significant difference in the mean scores of different values developed through Value Clarification and Role Playing Models.

\subsection{Design of the study}

It was found that both of the aforementioned approaches had their pros and cons. In this study, an attempt was made to study the comparative effectiveness of role-playing and value-clarifications Models by making two identical groups and subjecting both the groups under two different Value development models, namely Role Playing and Value Clarification for a month. After 1 month, value test was given to both the groups to observe comparative effectiveness of the above said Value Development Models. Hence, specifically the design may be termed as two groups, Post- Test Experimental Design.

\subsection{Sample and Sampling} Stage-I

The sample in the present study was drawn as follows at various stages.-

Sample of experts to Identify the most relevant values

Initially, to identify values for primary school children, 50 expert opinions were taken. These experts belonged to the fields of Education, Psychology, Government Education Departments, Primary school Principals and some Administrators.

\section{Stage- II \\ Selection of Institution}

A list of English Medium primary schools was prepared. From this list one institution was drawn randomly by lottery method.

\section{Stage-III}

\section{Selection of students}

Initially, all the students studying in various sections of class $\mathrm{V}$ in the selected institution were taken in the sample whose number was 130 . Out of the 130 students, two groups each having 30 students were formed randomly. While randomizing it was assumed that the students studying in the school have come from almost same background.

\subsection{Description of the tools}

Three types of tools were used in this study. All the tools were constructed by the investigator herself. A detailed description of the tools is given below:

\section{Identification of values}

To identify the most relevant values for primary school children, opinions of 32 experts from various fields were sought. For this, they were asked to write ten values which were most relevant in the present context for primary school children. After analyzing the data the most desired values were ranked in order of preference. Out of these 10 values, 6 top ranked values were included in the study. Since the tally marks in the last 4 values were less, they were discarded. The values which were identified as most relevant were -Honesty, Patriotism, Compassion, Truthfulness, Punctuality and Bravery.

\section{Preparation of items / situations}

\section{(A) Value Clarification Scale}

This procedure intends to help the learners define their own values and make them aware of other values. The students were asked questions and presented with situations and expected to respond to them. The process comprised of three steps:

a. Prizing ones belief and behaviour

b. Choosing ones belief and behaviour

c. Acting on ones belief.

No answers are considered right or wrong. This model provides the means for the individual to discover ones values that are considered important. Value Clarification may be attempted through techniques with reference to a single individual or groups. The students may report critical incidents of theirs. A survey of related studies pertaining to value measurement and value inculcation revealed that there is hardly any Value Clarification 
scale, that too for Primary and Elementary school children. Simon, Howe and Kirschenbaum (1978) suggested some strategies for value clarification but such scales are found to be lacking. Hence the investigator decided to develop a tool for inculcating identified values with the help of value clarification scale. The following steps were followed-

(A) Preliminary draft

Since the basic purpose of this tool was to inculcate the six identified values, Situations were made based on these values.

(B) Role playing scale

Detailed research showed that there was no appropriate scale on Role playing on the 6 values available. Before initiating, the students were asked to enact the Role -Playing situation on Bravery. It was found that some of the students were finding it difficult to place themselves in the situation as they were unable to correlate themselves with the situation. So initially the investigator first tried to talk to the students in order to derive the situations for role-playing from them. Situations were made for each value after a thorough discussion. Main idea behind this was that the students may become familiar with Role- Playing method. This resulted in the making of the first draft. 32 experts opinion of value were taken and the changes pointed by them were incorporated. Now keeping this in mind two of the situations were changed, one was deleted and one new situation was included.

(C) Value Assessment scale

To make an assessment of the inculcated values among primary school children in both the experimental groups where two different value development models were used, a value assessment scale was prepared by the investigator. Initially 48 statements based on the 6 identified values were made, corresponding to each statement 5 alternatives were given. These alternatives were Strongly Agree (SA), Agree (A), Indifferent (I), Disagree (DA) \& Strongly Disagree (SDA). This initial draft of the scale was given to various experts for improving the statements. After collecting the opinions, only those statements were included in the final draft on which there was consensus. Finally, 33 statements were left. The final draft was followed by instructions as follows.

\subsection{Procedure}

Formation of groups

Since the aim of the study was to assess comparative effectiveness of two Value Development Models, two groups of class V students were made. Out of 120 students, studying in class V, two groups of 40 children each were randomly formed. On one group, experimental treatment for Value Clarification (Value Development Model) was conducted and on the other Group -Role Playing Model was tried as experimental treatment.

Data Collection

First of all, permission was sought from the Principal of the institution. Two groups of students were first introduced with the purpose of the study and then actual work was started a day after. On the same day, the researcher undertook the situations for Value Clarification and Role playing in two periods. This treatment took a span of one month

\subsection{Administration of the scale}

(1) Value Clarification

The students were given the instructions about the situation with the probing questions. They were asked to answer as to what they felt they would do in the situation like that and what they thought about those questions. They were also told that there was no such thing as right or wrong .The students answered in writing, to the probing questions, in 15 situations based on the 6 values. Then a discussion amongst the students took place, where each situation was discussed. The investigator also participated in the discussion and tried to clarify where ever required. It took a month to administer the situations.

(2) Role Playing

The students were asked to enact the situation. This took place in the form of phases, according to Shafter and Shafter (1967)

Phase-I: This was warming up of the students. The students were introduced to the situation, so that they recognized it. The problem was made explicit. The students tried to interpret and then explore the situation. They were explained about role-playing.

Phase-II: Next, for each situation the participants were selected and the investigator described the various characters, as to what they were like, how they felt and what they might do. In short the roles were analyzed.

Phase-III: The stage was set, i.e. the role players outlined the scene but no specific dialogue was prepared. A few simple probing questions were asked by the investigator regarding the enactment .The situation was given but no ending was provided. The students were asked to get inside the problem situation. 
Phase-IV The observers i.e. the students who were not participating in the enactment were also actively involved. Thus the entire group might experience the enactment and later on analyse the play. The investigator assigned observation task, such as evaluating the realism of role playing and to decide what to look for. Comments on its effectiveness and portrayal of the feelings and ways of thinking of the students were initiated by the researcher. The observers had to determine whether the actions of role players were helpful or not. So the observers were prepared.

Phase-V Actual enactment in the form of role-play began by spontaneous enacting and the 'live' roles of enactors responded realistically to one another. The role playing is not expected to be a smooth dramatization, nor is it expected that each role player would always know how to respond. Then there was a break at role playing.

Phase-VI Discussion and evaluation of the problem took place. The participants and the observers were equally and intellectually involved. The review action of role play in terms of events, positions and realism took place. The discussion was spontaneous and its focus was on different interpretations of the portrayal and on disagreements over the roles was carried out. Yet, the consequences of the action and motivation of the enactment are considered more important. The researcher then focused the discussion on the aspects of developing the next enactment.

Phase-VII Re-enactment of the situation took place a number of times, till all the students were able to share all the interpretations of the roles and revised the roles of the play. Suggestions for next steps and behavioral alternatives were decided. This phase alternated between discussion and acting.

Phase-VIII Discussion and evaluation followed the second enactment. Students were willing to accept the solution but the researcher pushed for a realistic solution by asking whether they thought it could really happen. Thus this step was similar to Phase VI.

Phase-IX Experiences were shared and generalized, though in human relations it is difficult to reach a generalization in such a short span. The researcher attempted to shape the discussion so that the students were able to relate the problem-situation to real experience and generalize the approach to the current problemsituations and explore the consequences of those general principles of behaviour.

(3) Value Assessment Scale

To avoid blind ticking of statements, the students were instructed to read carefully the statements. Keeping in mind these suggestions 9 statements were deleted and 2 were added. Thus, there were a total of 33 statements. A tryout was carried out in order to know the difficulties that the students might face during the process of administering the scale. Both the groups of students of Role Playing and Value Clarification Model were given the test. The students were given instructions and later, on finishing it, the scale was collected and scoring was done according to the scoring key developed by the investigator.

\section{Statistical Techniques}

The qualitative analysis of data was done by finding frequencies of various responses given by students, but for comparing the effectiveness of two Value Development Models, Mean, SD and tests were used.

Value 1: Honesty

TABLE no. T-4.22 showing N, Mean, SD \& t value:

\begin{tabular}{|c|c|c|c|c|}
\hline Models & N & M & SD & t \\
\hline VC & 30 & 19.17 & 6.28 & \multirow{2}{*}{1.96} \\
\hline RP & 30 & 21.63 & 2.88 & \\
\hline
\end{tabular}

Value 2: Bravery

TABLE no. T-4.23 showing N, Mean, SD \& $t$ value:

\begin{tabular}{|c|c|c|c|c|}
\hline Models & N & M & SD & t \\
\hline VC & 30 & 19.73 & 5.75 & \multirow{2}{*}{0.17} \\
\hline RP & 30 & 19.93 & 2.72 & \\
\hline
\end{tabular}

Value 3: Compassion

TABLE no.T-4.24 showing N, Mean, SD \& $t$ value:

\begin{tabular}{|c|c|c|c|c|}
\hline \multirow{2}{*}{ Models } & N & M & SD & \multirow{2}{*}{ t } \\
\hline VC & 30 & 20.37 & $\mathbf{6 . 0 2}$ & \multirow{2}{*}{0.08} \\
\hline RP & 30 & 20.47 & 3.60 & \\
\hline
\end{tabular}

Value 4: Patriotism 
TABLE no. T-4.25 showing N, Mean, SD \& t value:

\begin{tabular}{|c|c|c|c|c|}
\hline Models & N & M & SD & t \\
\hline VC & 30 & 22.73 & 6.32 & \multirow{2}{*}{0.64} \\
\hline RP & 30 & 23.53 & 2.57 & \\
\hline
\end{tabular}

Value 5: Punctuality

TABLE no. T-4.26 showing N, Mean, SD \& t value:

\begin{tabular}{|c|c|c|c|c|}
\hline Models & N & M & SD & t \\
\hline VC & 30 & 20.93 & 6.59 & \multirow{2}{*}{1.92} \\
\hline RP & 30 & 23.50 & 3.23 & \\
\hline
\end{tabular}

Value 6: Truthfulness

TABLE no. T-4.27 showing N, Mean, SD \& t value:

\begin{tabular}{|c|c|c|c|c|}
\hline Models & N & M & SD & t \\
\hline VC & 30 & 14.90 & 4.63 & 2.45 \\
\hline RP & 30 & 15.77 & 0.91 \\
\hline
\end{tabular}

\section{Results and Discussion}

The situations developed for the two Development Models have been done so after a lot of consideration and exploring avenues with children. Situations in both cases of Development Models have been made to find what the children assess at face value. For example, in one of the situations a boy, even though in dire need still returns the money to the customer who had given it to him by mistake. The children who were not at such a high stage of thinking, made their judgment on the basis of monetary value of the said transaction. If a child evaluates the intent over the repercussions and then assesses, then he would actually be securing a much more sublime stage of thinking. The situations were related to both the Value Development Models. If a child considers the intentions behind the act he may argue that while it may be deemed wrong to tell a lie, but certainly not so bad, if it is told to save some one's life.

So the child is giving preference to the value represented in that particular act. Hence, it can be postulated that the consideration of values is inherent in the technique. Each situation presents a value related conflict to be resolved by the child through Value Clarification and Role Playing. The purpose of the situations in this study was to help out the pupils in progression of lower level of values to a higher stage of values. Each situation was related to a particular value. It gives rise to judgmental conflict regarding these values. Here the purpose has been to assist the children in acquisition of a positive value without any adult constraint. Since the child is motivated to resolve the conflict through self- thinking, it is assumed that the child moves a step towards acquiring that particular value. It may be a slow purpose but is decidedly an effective one.

The reason behind the selection of these values was that the children selected for this study were of the age group when the child becomes involved in the school world and peer group. He associates himself to the group. Simultaneously he becomes aware that adult rules are often in conflict with the individual needs. They are required to take decisions and make judgments in accordance to priority. They ponder if they should lie to protect a friend or tell the truth, due to which their friend may get into trouble. The ability to take decision requires the ability to take the perspective of others, quality of empathy and a higher level of emotional strength and love of country. All these qualities are inherent in these values, and certainly the most needed values to be inculcated in children at this age.

\section{Conclusion}

The situations were created in such a manner that the above stated values were prevalent in all situations. The children were given opportunities to internalize the value through resolution of the conflict. The situations provided the children with role playing opportunity so as to identify themselves with the main character of the situation. The conflict of the main character becomes the child's own conflict. Through intervention and constant discussion it is aimed to help the children consider and discuss the various choices and possible outcomes. The conflicts in each situation presents two choices, one-taking the easier way out - by giving in to social constraint, the second choice is more painful because the effects of the decision may be in the form of adult disapproval. The acceptance of the second alternative by the child means that he is moving up in his value inculcation, by accepting the possible value represented in the situation; though at times the decision making becomes very tedious since the line between the two might be very thin.

On conducting the study and comparing it was found that both the Value Clarification Model and Role Playing Model proved to be nearly equally effective as far as the inculcation of the selected values was concerned. The previous studies conducted had shown that Role Playing Model on primary school children was 
more effective than Value Clarification Model. The research showed that the comparative study conducted on the class V students showed nearly the same effectiveness.

After a careful examination of the above two models and their efficiency in the classroom scenario today, one can state without doubt that these, if implemented, should relieve the current degradation in today's society. By building on their morals the students will transform not just into responsible adults but also responsible human beings.

\section{References}

[1]. Allport, G.W.Vernon P.E and Lindzy, G.(1960): A study of Values, Haughton Miffilin,Boston.

[2]. Rokeach,M. (1973): The Nature of Human Values. The free Press A Division of Mac Millan Pub.co. New York.

[3]. Raths et al (1966): Values and Teaching, Columbus. Ohio: Charies E. Merrill.

[4]. Shaver,J.and William,S (1976): Facing Value Decision; Rational Building for Teachers, Wordshorth Belmont.

[5]. Kirschenbaum, H and Simon, S.B. (Eds.) (1978): Readings in Value Clarification, Minneapolis, Winston Press.

[6]. Buch, M.B. (1974): A survey of Research in Education, Centre of Advance study in Education, NCERT, New Delhi

[7]. Das, R.C. (1987): Education in Values, Journal of Indian Education, 13 (4), 37-41

[8]. Gupta, K.M. (1991 a): Stage Structure of Teacher Educators in moral judgement, Indian Education Reviews, 26(2), 61-68

[9]. Jangira,N.K. (1983): Using Value Clarifying Strategies in the class room. The Primary Teacher ,8(2), 18-21

[10]. Joyce, B.: Weil, M. and Showers, B. (1992): Models of Teaching. New Delhi: Prentice Hall of India.

[11]. Malhotra ,S.P. (1984): Teaching Values in the class : Jurisprudential technique. The Education Quarterly, 36(4),9-11

[12]. Mathur, V.S. (1983): Value based education, Journal of Indian Education, 8(5),31-34

[13]. National Policy on Education (1986): Government of India, Ministry of Human Resource Development, Department of Education, New Delhi

[14]. NCERT (2000): National Curriculum Framework for School Education, NCERT, New Delhi.

[15]. NCERT (2003): Value education in Indian school: Experiences and strategies of Implementation National Consultation Value Education, NCERT, New Delhi.

[16]. Secondary Education Commission (1952-53): Government of India, Ministry of Education, New Delhi

[17]. Seshadri, C. (1982): Moral Education: Some points to ponder. The Education quarterly, 34 (3), 1-4

[18]. Shaftel, F.R. and Shaftel, G. (1967): Role-playing for Social Values: Decision-Making in the Social Studies. Englewook Cliffs, New Jersy: Prentice Hall.

[19]. University Education Commission (1948-49): Government of India, Ministry of Education, New Delhi

[20]. Oxford Dictionary and Thesaurus Dictionary, Oxford University Press, U.K 2005 